\title{
A proposta de parceria transatlântica de comércio e investimentos: uma visão a partir do debate macroeconômico
}

\author{
André Luís Cabral de Lourenço ${ }^{1}$ \\ Aline Michele da Silva \\ Genival Porfírio do Nascimento Neto ${ }^{2}$ \\ Helderlane Carneiro Alves ${ }^{2}$ \\ Laetitia Henriette Piroit ${ }^{2}$ \\ Maria Alessandra Nunes da Silva² \\ Valéria Cristina de Souza Lima Galvão de Sena²
}

\begin{abstract}
Resumo: A Parceria Transatlântica de Comércio e Investimentos é uma proposta do governo Obama para ampliação dos laços comerciais entre EUA e União Europeia. O presente artigo tem por objetivo avaliar dois conjuntos de trabalhos - ortodoxo e heterodoxo - que buscam avaliar os impactos macroeconômicos e setoriais dessa iniciativa. Usando como referência a literatura macroeconômica contemporânea para examinar as bases teóricas subjacentes aos dois conjuntos de contribuições, conclui-se que ambos enviesam o resultado da análise dos impactos do possível acordo, embora em direções opostas. $\mathrm{O}$ consequente prejuízo sobre o debate público pode ter contribuído para seu virtual congelamento pelo governo Trump.

Palavras-chave: Parceria Transatlântica de Comércio e Investimentos. Impactos macroeconômicos e setoriais. Macroeconomia.
\end{abstract}

The proposal for a transatlantic partnership for trade and investment: a view based on the macroeconomic debate

\begin{abstract}
The Transatlantic Trade and Investment Partnership is a proposal by the Obama administration to expand trade ties between the US and the European Union. The objective of this article is to evaluate two sets of works - orthodox and heterodox - that seek to evaluate the macroeconomic and sectoral impacts of this initiative. Using contemporary macroeconomic literature as a reference to examine the theoretical underpinnings underlying the two sets of contributions, we conclude that both bias the outcome of the analysis of the impacts of the possible agreement, albeit in opposite directions. The resulting damage on the public debate may have contributed to its virtual suspension by the Trump administration.

Keywords: Transatlantic Trade and Investment Partnership. Macroeconomic and sectoral impacts. Macroeconomics.

Classificação JEL: F13, E17, F17
\end{abstract}

1 Professor do Departamento de Economia da UFRN. E-mail: andre.lclourenco@gmail.com

2 Alunos do curso de graduação em Economia pela UFRN. 


\section{Introdução}

A proposta de Parceria Transatlântica de Comércio e Investimento (doravante TTIP), tornada pública em fevereiro de 2013, foi a mais importante iniciativa da gestão Obama no campo do comércio internacional. Em conjunto com seu congênere Acordo de Associação Transpacífico, constituiu significativa mudança na estratégia estadunidense de condução a nível global da agenda pró-livre comércio (ou mais propriamente "comércio justo", na terminologia oficial). Denotou, neste particular, a ampliação de esforços na busca de soluções geograficamente mais limitadas, em detrimento do esforço de âmbito global da até aqui malfadada Rodada de Doha da Organização Mundial de Comércio (OMC). A ausência da China e da Rússia de ambos os acordos denota ainda importante passo adicional no esforço geopolítico sistematicamente empreendido pelos EUA desde o fim da Guerra Fria, visando reforçar seus laços militares, políticos e econômicos com seus aliados tradicionais em detrimento desses países.

A TTIP pretende aumentar os laços comerciais entre a segunda maior economia mundial, a União Europeia (UE), e a terceira maior, os EUA, cujos PIBs em 2015 eram, respectivamente, de US\$ 19,2 e US\$ 17,9 trilhões de dólares (medidos em unidades de paridade de poder de compra, PPC), conforme dados do FMI (2016). Juntas, portanto, essas economias constituem um mercado cujo volume é quase o dobro do mercado chinês, e que corresponde a aproximadamente um terço do PIB mundial. Segundo a UE (2015), porém, o comércio bilateral em 2014 foi de $€ 517$ bilhões, ou seja, cerca de $2 \%$ do PIB conjunto. É sobre esse valor que o acordo de fato incide, sendo cinco os temas principais do acordo.

A literatura sobre o comércio entre EUA e UE é unânime em afirmar a pequena importância das barreiras tarifárias no cenário atual. Em relação às importações americanas de produtos europeus, a proteção média é de $1,7 \%$ para os produtos manufaturados, e 6,6 \% para produtos agrícolas. O setor de leite e lacticínios é o mais sensível, com tarifa média de $22 \%$. Do lado europeu, a proteção está focada principalmente na agricultura, com média de 12,8\%, em comparação ao valor de 2,3 \% para os manufaturados. O setor da carne é o mais sensível, com média de proteção de $45 \%$, área em que os produtores estadunidenses são muito competitivos, e que foi responsável por quase $20 \%$ das exportações mundiais em 2010.

Muito mais importantes para o sucesso do acordo do que as tarifas são as negociações em torno das medidas não tarifárias (MNTs) existentes, que incluem, nas manufaturas, proibições de importação e certificação de requisitos sobre uma grande variedade de produtos, desde brinquedos a carros e marca-passos; informações sobre as propriedades de produtos químicos; requisitos de rotulagem; embalagem e os limites máximos sobre a concentração de resíduos de pesticidas, entre outros. Esses 
obstáculos incluem ainda medidas sanitárias e fitossanitárias, regulamentos e outras barreiras técnicas ao comércio. As negociações são mais complexas em relação às medidas sanitárias e fitossanitárias, pois a percepção de risco nos dois lados do Atlântico é diferenciada.

Em relação aos serviços, a regulação é projetada para, em tese, proteger o consumidor, como nos setores bancário e de seguros. No caso da UE e dos EUA, a conjunção de dois eventos está aumentando a complexidade das negociações sobre serviços. Um deles é o atual processo de desregulamentação do serviço postal europeu combinado com o choque tecnológico sofrido pelo setor (correio eletrônico). O segundo é a crise financeira, que levou a maior regulação do setor.

A contratação pública é outro campo importante de negociação. De acordo com as estimativas de Cepii (2013), a quota de contratos públicos abrangidos por compromissos no âmbito do Acordo de Contratações Públicas da Organização Mundial do Comércio é de $95 \%$ para a UE e de $32 \%$ para os EUA.

O investimento é potencialmente uma parte importante do acordo, em especial na proteção dos interesses dos investidores contra as medidas nacionais discriminatórias ou descompensadas.

Vale ainda ressaltar que um fator importante para a Europa é a proteção e valorização de suas tradições artísticas e gastronômicas ricas e diversificadas, em especial a França, demandando salvaguardas diversas.

Tão logo foi proposto, o acordo deu lugar à ampla discussão desses diversos aspectos. Do debate acadêmico, o tema saltou para as manchetes da grande mídia global quando o agora Presidente Donald Trump colocou como uma das suas principais bandeiras durante a campanha presidencial o abandono (recentemente consumado) do congênere Acordo de Associação Transpacífico e a revisão de vários acordos comerciais vigentes.

Este artigo pretende, porém, abordar o tema pelo prisma acadêmico, concentrando-se no seu aspecto macroeconômico. Em particular, busca-se avaliar o debate acadêmico sobre o tema à luz dos modelos macroeconômicos e das hipóteses teóricas empregadas nessa discussão. A hipótese é que a escolha dos modelos macroeconômicos usados nos trabalhos acadêmicos foi crucial para os resultados obtidos, tanto nos artigos que sustentam posições favoráveis ao acordo, quanto nos que suportam a oposição a ele.

É conveniente, no que se segue, aglutinar a literatura relevante em dois grandes grupos. O item 2 se dedicará a analisar os trabalhos acadêmicos que sustentam visões favoráveis ao acordo, enquanto o item 3 tratará dos que suportam as posições opostas. O item 4 critica esses dois blocos de contribuições, e o último item conclui a discussão. 


\section{Visões favoráveis ao acordo}

O item a seguir trata das principais contribuições acadêmicas favoráveis à implantação do TTIP. O subitem 2.1 introduz o relatório do Ecorys (2009), peçachave para avaliação do acordo. A seguir, Felbermayr et al. (2013), referido como Bertlesmann (2013), é apresentado no subitem 2.2. No subitem 2.3, exploram-se os elementos principais de François et al. (2013), aqui denominado CEPR (2013), enquanto o subitem 2.4 é dedicado ao exame de Fontagné et all. (2013), aqui Cepii (2013). O item 2.5 sintetiza e compara os principais resultados dos estudos resenhados neste item.

\subsection{Ecorys (2009)}

O relatório "Non-Tariff Measures in EU-US Trade and Investment - an Economic Analysis" foi encomendado pela UE junto a um consórcio de empresas liderado pela Ecorys. Partindo da percepção de que as barreiras tarifárias ao comércio e investimento norte transatlântico já eram extremamente exíguas, estabeleceu-se como principal objetivo avaliar detalhadamente os efeitos das barreiras não tarifárias (NTMs) sobre o PIB, renda familiar, salários e comércio, incluindo o estudo pormenorizado do seu impacto em 12 grandes setores ${ }^{3} \mathrm{e}$, em menor detalhe, de outros 10 setores $^{4}$. Com base em tal avaliação, estimou-se o resultado da redução e alinhamento de NTMs por um horizonte de dez anos. O relatório se tornou assim uma das principais referências para a tomada de posições e decisões nas negociações acerca do TTIP para as autoridades europeias (OFSE, 2014).

A metodologia do estudo incluiu diferentes métodos e fontes de informação para estimar o tamanho relativo das NTMs setorialmente em ambos os parceiros ${ }^{5}$. O instrumental econométrico das regressões de gravidade foi então empregado para estimar o impacto dessas NTMs nos fluxos de comércio e investimento. Dadas certas suposições acerca do tamanho esperado de redução das $\mathrm{NTMs}^{6}$, um modelo de Equilíbrio Geral Computável (denominado GTAP) foi então utilizado para estimar as

3 Setor aeroespacial; automóveis; químicos; cosméticos; eletrônicos; alimentação e bebidas; farmacêuticos; serviços de comunicações; serviços financeiros; seguros; serviços de transporte; e equipamentos de escritório, informação e comunicações.

4 Serviços de viagens; construção; serviços pessoais, culturais e de recreação; biotecnologia; maquinaria; equipamentos médicos, de mensuração e de teste; produtos siderúrgicos e metalúrgicos; têxteis, vestuário e calçados; madeira, papel e derivados; e outros.

5 A metodologia combinou revisões de literatura, análise econométrica, questionários aplicados às empresas, entrevistas com especialistas do setor, e também consultou índices sobre restrições e regulamentos vigentes. As médias setoriais que foram obtidas a partir dessas metodologias podem ser interpretadas como um índice relevante de medidas não tarifárias.

6 Dois cenários, otimista e realista, com redução de NTMs de, respectivamente, 50 e $25 \%$. 
mudanças macroeconômicas totais na renda nacional, salários, emprego, exportações e importações daí decorrentes, bem como seus impactos setoriais.

O relatório diferencia quatro tipos de bens e serviços para conduzir a análise setorial, com base em duas características: tipo de comércio relevante (transações à distância ou proximidade geográfica) e as características dos produtos e serviços (padronizado ou customizado), criando reflexos nas diversas divergências reguladoras entre os setores.

Os resultados macroeconômicos totais ou parciais de reduções das NTMs e harmonizações das divergências reguladoras, no cenário otimista, implicam:

- Crescimento adicional do PIB de 0,7 \% ao ano na União Europeia e de 0,3 \% ao ano nos EUA;

- Aumentos salariais reais adicionais, devido aos ganhos de produtividade, de $0,4 \%$ ao ano na UE e de 0,8 \% ao ano nos EUA, tanto para trabalho qualificado quanto para não qualificado;

- Crescimento de 6,1 \% nas exportações estadunidenses e de 2,1 \% nas europeias;

- Crescimento das exportações líquidas de ambos os sócios, denotando ganhos de competitividade de ambos em relação ao resto do mundo;

- A UE ganha mais com acesso a produtos mais baratos, e ambos ganham com a redução dos custos de produção;

- Parte significativa dos ganhos de comércio decorre dos efeitos de encadeamento entre setores, e não tanto dos efeitos dentro dos setores.

Importante notar a ausência de menção a qualquer efeito (ainda que temporário) sobre o desemprego.

Com relação aos ganhos de renda setoriais, destacam-se: 1) na UE: a) veículos a motor; b) químicos, cosméticos e farmacêuticos; c) alimentos e bebidas; e d) maquinário elétrico; 2) nos EUA: a) maquinário elétrico; b) seguros; c) serviços financeiros; e d) químicos, cosméticos e farmacêuticos.

Observando-se o panorama do ponto de vista da produção setorial, destacam-se as mudanças no setor de equipamentos de escritório, informação e comunicações, com aumento de $29 \%$ nos EUA e queda de 5,5\% na UE; veículos motorizados, que diminuiriam 1,4 \% nos EUA e aumentariam 5,7 \% na UE; e os produtos químicos, cosméticos e fármacos, que aumentariam 3,3\% nos EUA e 2,2 \% na UE.

Do ponto de vista das exportações, o maior crescimento se deu: a) $\mathrm{Na} U E$, em veículos motores; químicos, cosméticos e farmacêuticos; e seguros; b) Nos EUA, em maquinário elétrico; aeroespacial; e produtos metalúrgicos.

Como é típico nesse tipo de literatura, o acordo comercial é visto como ampliador do bem-estar para todos os países envolvidos ("solução ganha-ganha"), em função dos ganhos alocativos da maior especialização. Estas propiciam então custos e preços mais baixos ao longo das cadeias produtivas afetadas, que permitem ampliação 
da demanda pelos seus produtos. Chama atenção, contudo, a falta de menção a possíveis efeitos colaterais negativos, ainda que temporários.

\subsection{Bertelsmann (2013)}

A primeira parte desse estudo é dedicada aos efeitos macroeconômicos da TTIP $^{7}$. Foram utilizados os modelos empíricos da economia mundial para estabelecer dois cenários: a eliminação de tarifas no comércio entre a UE e os EUA ("Eliminação de tarifas") e uma liberalização que inclui a remoção de barreiras não tarifárias ("Liberalização ampla"). O segundo cenário foi gerado replicando-se a experiência de criação de comércio de acordos semelhantes $(\approx 80 \%$ no agregado), e não pelo método tradicional de estabelecer aprioristicamente o acordo considerado possível pelo prisma político.

Foram geradas estimativas dos efeitos do acordo sobre os fluxos comerciais mundiais (126 países), o PIB per capita e o desemprego friccional ${ }^{8}$ para cada membro da UE individualmente, para os dois cenários. A base para tais estimativas foi o modelo teórico de equilíbrio geral computável desenvolvido no próprio Instituto IFO (Felbermayr et al., 2013a), que combina métodos econométricos e de simulação. Os resultados obtidos podem ser assim sintetizados:

- Em geral, a mera redução das tarifas remanescentes não afeta significativamente o comércio, o PIB real e nem o emprego, enquanto o cenário de liberalização ampla implica efeitos muito maiores nessas variáveis, com um aumento do comércio entre EUA e UE de cerca de $90 \%$; em função disso todos os demais pontos abaixo se referem ao efeito do cenário de liberalização ampla;

- Há aumento da renda por habitante tanto nos EUA quanto na UE, mas o dos EUA é substancialmente maior do que o europeu (13,4\%);

- O aumento médio do PIB per capita na UE é de 4,95\%; os países bálticos, os mediterrâneos e o Reino Unido são os maiores ganhadores, enquanto França, os países da Benelux e Áustria são os menores. As simulações mostram que o acordo não contribuiria para causar maior divergência das condições de vida na Europa. Na verdade, o oposto é mais provável.

- Devido à reversão parcial do desvio de comércio gerado pela criação da União Europeia, o comércio intraeuropeu sofre significativa redução; para os países

7 A segunda parte do estudo, que não foi aqui tratada, explicita os efeitos setoriais do acordo apenas sobre a economia alemã.

8 Repare que se trata de efeitos indiretos do comércio, que afetam o desemprego friccional através do custo de procura de empregos, e não do efeito direto na demanda agregada e no desemprego involuntário. Estes estão afastados do modelo por hipótese, em função da construção teórica empregada. 
individualmente, porém, o efeito é mais do que compensado pela ampliação do comércio com os demais países;

- Embora haja fortalecimento do comércio entre EUA e UE, há evidente desvio de comércio dos demais países. Por exemplo, há redução do comércio dos BRICs tanto com os EUA (em maior escala) quanto com a UE (em menor escala); Brasil ${ }^{9}$, Cazaquistão e Indonésia são exceções, pois como são importantes fornecedores de matérias-primas para a Europa e os EUA, obtêm ganhos de renda pelos efeitos indiretos do comércio;

- Haveria queda significativa do desemprego friccional (média de 0,5 pontos percentuais) não só nos EUA e UE, mas também na média da $\mathrm{OCDE}^{10}$, implicando criação de mais de 2 milhões de empregos; o desemprego cai mais nos países em que ele inicialmente era maior, tendendo a homogeneizar os mercados de trabalho. Há ainda ganhos de salário real médios de 2,3\% (maiores nos EUA, Irlanda e Grã-Bretanha).

Em suma, o estudo não só prevê efeitos do tipo "ganha-ganha" para todos os participantes do acordo em termos de comércio, renda e emprego, como ainda que tais ganhos, ao menos na UE, tenderiam a ser maiores nos países mais atrasados. Se aplicam as mesmas qualificações feitas no item anterior a Ecorys (2009).

\subsection{CEPR (2013)}

O relatório Reducing Transatlantic Barriers to Trade and Investment: An Economic Assessment foi contratado pela UE frente à rede de pesquisadores do Centre for Economic Policy Research (CEPR), e segundo Capaldo (2014), foi o principal documento de suporte ao acordo na Europa. Como os anteriores, ele também pretende examinar o impacto da redução de barreiras não alfandegárias ao comércio, chamando, porém, atenção para o fato de que, ao contrário das tarifas, muitas regulamentações não podem ser simplesmente removidas, pois servem frequentemente a objetivos nacionais importantes e legítimos, como segurança e proteção ao ambiente e ao consumidor. Mesmo assim, considera-se que os custos por elas gerados podem ser mitigados por convergência regulatória e reconhecimento cruzado de padrões.

As barreiras tarifárias existentes na UE e nos EUA são heterogêneas. $\mathrm{Na}$ maioria dos setores, as tarifas europeias são ligeiramente maiores que as norteamericanas, embora sejam relativamente baixas. As únicas exceções são os setores de veículos a motor e alimentos processados. O primeiro (8\%) apresenta uma tarifa

9 Vide Lopes da Silva et al. (2017) para estimativas alternativas sobre o Brasil.

10 Alguns países, contudo, teriam perdas, a maior das quais no Canadá (100 mil). Por escassez de dados, o relatório só inclui o efeito no mercado de trabalho dos países da OCDE. 
quase oito vezes maior que a tarifa norte-americana e o segundo $(14,6 \%)$ é quatro vezes maior que o dos EUA. A agricultura, silvicultura e a pesca apresentam tarifas relativamente elevadas, porém, não existe muita diferença entre as duas economias. Dessa maneira, as reduções tarifárias implicariam em mudanças relativamente pequenas. No entanto, nos setores de veículos a motor e alimentos processados, o impacto é provavelmente mais substancial.

O estudo se baseia no mesmo modelo de Equilíbrio Geral Computável (GTAP) do comércio mundial global usado em Ecorys (2009). Dois grandes cenários são estipulados, cada um deles subdividido em certo número de subcenários. $\mathrm{O}$ primeiro dos grandes cenários é o de acordo limitado, subdividido em três subcenários: 1) redução apenas de tarifas; 2) redução de MNTs apenas de serviços; 3) redução de restrições apenas a compras governamentais. $\mathrm{O}$ segundo grande cenário é o de acordo abrangente (redução de tarifas e MNTs em bens, serviços e compras governamentais), subdividido em dois subcenários: 1) pouco ambicioso (redução de $98 \%$ das tarifas e de $10 \%$ do custo gerado pelas MNTs); e 2) mais ambicioso (redução de $100 \%$ das tarifas e de $25 \%$ do custo gerado pelas MNTs).

Tabela 1 - Resumo dos efeitos econômicos do acordo, segundo o grau de liberalização, sobre a variação do PIB na UE, estimados por CEPR (2013), em bilhões de euros

\begin{tabular}{|c|c|c|c|}
\hline & & $\begin{array}{l}\text { Acordo abrangente } \\
\text { menos ambicioso }\end{array}$ & $\begin{array}{c}\text { Acordo abrangente } \\
\text { mais ambicioso }\end{array}$ \\
\hline \multirow{2}{*}{ Variação do PIB } & UE & 68,27 & 119,21 \\
\hline & EUA & 49,54 & 94,90 \\
\hline \multirow{2}{*}{$\begin{array}{l}\text { Variação das } \\
\text { exportações }\end{array}$} & UE & 125,23 & 219,97 \\
\hline & EUA & 142,07 & 239,54 \\
\hline
\end{tabular}

Fonte: CEPR (2013).

Os resultados obtidos mostraram-se positivos e significativos para ambas as economias. A primeira conclusão a se retirar é que o acordo limitado conduz a aumentos relativamente pequenos no PIB nas duas economias. Para a UE, os cortes tarifários levariam a um aumento de $10 \%$ do PIB, enquanto a redução das barreiras não tarifárias nos serviços e nas compras governamentais levaria ao aumento do PIB de apenas $2 \%$. Em relação aos EUA, reduções tarifárias provocariam um aumento de $4 \%$ do PIB, já as barreiras não tarifárias, de $3 \%$ e de $1 \%$.

Os efeitos provocados pelo acordo seriam distintos entre os diferentes setores da economia dos EUA e da UE. As alterações estimadas nos setores específicos de produção são muito pequenas. Nenhum dos setores irá aumentar ou diminuir mais que $1 \%$ e, em alguns casos, a saída ficará inalterada, como no da UE. Já para os EUA, apenas dois setores da produção iriam variar mais que $1 \%$, 
que é o caso de um aumento dos veículos a motor de $1,76 \%$ e uma queda na maquinaria elétrica de $1,40 \%$.

Em relação às mudanças nas exportações na UE, estimou-se um aumento de $3,37 \%$ no cenário menos ambicioso e de 5,91 \% no cenário mais ambicioso. Já as importações, apresentaram um percentual de 2,91 \% no menos ambicioso e 5,11 \% no mais ambicioso. O maior aumento seria no setor de veículos, $43,11 \%$ no cenário mais ambicioso, acompanhado de um aumento na produção desse setor para o mesmo cenário. As exportações totais americanas seriam de 4,75 \% e 8,02 \% no cenário menos ambicioso e ambicioso respectivamente, e em relação às importações, um valor $2,81 \%$ e $4,74 \%$ para os mesmos cenários. $\mathrm{Na}$ UE o setor de veículos sinaliza um maior destaque, contrariamente ao setor de serviços.

Nas mudanças setoriais ocorreria um aumento significativo total nas exportações da UE para os EUA de $16,16 \%$ e $28,03 \%$, para os cenários menos ambicioso e ambicioso, respectivamente. $\mathrm{O}$ destaque seria para setores de veículos com percentual de $71 \%$ no cenário menos ambicioso e $148,7 \%$ para o ambicioso, enquanto que o setor de serviços teria impactos negativos. As exportações dos EUA para a UE passariam por um aumento ainda maior $(23,20 \%$ para o cenário menos ambicioso e $36,57 \%$ para o ambicioso). O aumento seria mais notável no setor de veículos, em que ocorreria um aumento substancial de $207,40 \%$ e $346,80 \%$ nos cenários menos e mais ambicioso, respectivamente.

Estimam-se efeitos de realocação de trabalhadores em todos os setores, pois como o modelo EGC trabalha com o conceito de equilíbrio de longo prazo, só há desemprego estrutural, e os salários mudam o necessário para equilibrar os mercados de trabalho. Na UE, no setor de automóveis, o emprego expande em 1,28 $\%$ para mão de obra qualificada e 1,27 \% para menos qualificada. Em contraste, existe uma contração significativa de postos de trabalho nos setores de máquinas elétricas e metais. Nos EUA o setor de automóveis apresenta queda no emprego, enquanto ocorrerá aumento nos setores de metais e produtos metálicos. Setores como o de veículos a motor na UE e máquinas e outros equipamentos de transporte nos EUA acabariam atraindo trabalhadores de outros setores, ao oferecer salários mais altos. A circulação da força de trabalho não seria afetada em mais de 0,7 \% entre setores, com impacto maior para trabalhadores menos qualificados do que para os mais qualificados.

Um impacto relevante ocorreria em relação às emissões de $\mathrm{CO} 2$ e aos recursos naturais, que deverão aumentar cerca de 3 e 4 mil toneladas para UE e EUA, respectivamente. Já em relação aos recursos naturais, não haveria mudanças significativas em nenhuma das regiões.

No geral, um aumento do comércio entre UE e EUA impactaria positivamente em outras partes do mundo, especialmente na medida em que os padrões de regulação 
comum fossem adotados também por outros países. No cenário menos ambicioso, estima-se um ganho global de $€ 46,6$ bilhões, o que equivale a um aumento percentual de $0,07 \%$ do PIB, sinalizando um efeito positivo para as economias analisadas, sobretudo a Asean (Associação das Nações do Sudeste Asiático), em que se espera que o PIB aumente em 0,45\% e 0,89\% para os cenários menos ambicioso e ambicioso, respectivamente.

Como em Ecorys (2009) e Bertelsmann (2013), esse trabalho é favorável à iniciativa de liberalização do comércio entre EUA e UE, prevendo também soluções "ganha-ganha" para todos os envolvidos. Prevê ainda ganhos para o resto do mundo que, mesmo sem participar do acordo, colheria benefícios indiretos. Aplicam-se, portanto, as mesmas qualificações feitas aos trabalhos anteriormente tratados. Ressalte-se, porém, que foi o único trabalho favorável ao acordo a citar explicitamente o fato de que a metodologia empregada não cobre efeitos considerados de curto prazo (desemprego involuntário) no mercado de trabalho.

\subsection{Cepii (2013)}

Este estudo foi promovido por pesquisadores do Centro de Estudos Prospectivos e de Informações Internacionais (Cepii), sediado na França, e visa avaliar os impactos do TTIP. Utilizou, como os demais, um modelo de equilíbrio geral computável (denominado Mirage), mas com projeção dos impactos até 2035. Seu cenário de referência inclui a completa eliminação das tarifas e a remoção de $25 \%$ das MNTs (exceto contratos públicos e audiovisuais) ${ }^{11}$.

O cenário de referência sugere que o comércio de bens e serviços entre as duas regiões aumentaria pela metade. $\mathrm{Na}$ agricultura o comércio bilateral aumentaria em média $150 \%$ entre UE e EUA, com aumentos menores para os serviços. Os ganhos dos EUA na agricultura são 2,5\% maiores que os europeus, devido às diferenças iniciais no fluxo de comércio e níveis de proteção. Nos EUA a indústria química é responsável por mais da metade do aumento das exportações de produtos entre indústrias. Estimam-se ainda ganhos anuais do PIB no longo prazo de $€ 98$ bilhões para a UE, e $€ 64$ bilhões para os EUA.

Embora uma das preocupações do acordo seja o desvio de comércio, que não contribuiria para eficiência global, tendo em vista que exportadores de países terceiros se tornariam mais competitivos que os exportadores dos países dentro da FTA, no geral, pode-se detectar pouco desvio de comércio induzido pelo TTIP. Numa análise

11 Outros cenários são citados de passagem apenas, de modo que nos concentraremos nesse cenário de referência. Para maiores informações sobre os cenários alternativos, vide Cepii (2013: p. 11), em particular a Tabela 5, que sintetiza os respectivos ganhos em exportações e renda real. 
mais detalhada verificou-se que o México, o Canadá, a China e o Japão perderiam quotas de exportação no mercado industrial dos EUA em alguns setores.

Em relação aos impactos, seriam desiguais para os estados membros da UE, tendo em vista o cenário de referência. $\mathrm{O}$ aumento médio das exportações da UE será de $2 \%$ e de $10 \%$ para os EUA. O aumento esperado nas exportações britânicas é de $4 \%$, mais do que na França e na Alemanha, cujas taxas estão ao redor da média da UE, pelo fato dos EUA responderem por uma fatia maior das exportações no Reino Unido.

Considerando a distribuição setorial, observou-se um aumento de $5 \%$ nas exportações britânicas de serviços, mas também um aumento de $4 \%$ para a indústria. Para a Alemanha, os ganhos na indústria são semelhantes aos da média da UE (2\%), enquanto os ganhos em serviços (3\%) estão abaixo dessa média. Já as exportações alemãs de produtos agrícolas sofrerão impacto negativo.

Concluiu-se que no geral os EUA e a UE conseguiriam ganhos similares no PIB $(0,3 \%)$, correspondendo a um aumento de longo prazo de 98 bilhões na renda nacional. $\mathrm{O}$ ganho no valor adicionado para a agricultura dos EUA seria de $2 \%$, que na UE haveria perda de $1 \%$. Em contraste, os ganhos na indústria e serviços seriam maiores para a Europa. $\mathrm{Na}$ Alemanha e Reino Unido a agricultura sofreria impactos negativos, mas em compensação, suas indústrias e serviços aufeririam ganhos duplicados em relação à França.

Em que pese a versão mais simples do modelo de equilíbrio geral empregado neste estudo não especificar informações setoriais mais desagregadas, ele também gera, como os demais, soluções do tipo "ganha-ganha" para os envolvidos no TTIP. Não há qualquer menção a impactos negativos nos mercados de trabalho, ainda que temporários, das mudanças setoriais sugeridas.

\subsection{Uma comparação dos principais resultados dos trabalhos pró-TTIP}

A literatura, em especial OFSE (2014), oferece um interessante resumo das posições favoráveis ao acordo, que permite localizar mais facilmente os pontos de convergência e divergência entre essas visões. No que concerne aos cenários empregados, mostra que Ecorys estima reduções de $50 \%$ e $48 \%$ nas MNTs para as exportações da EUA-UE e UE-EUA, respectivamente, enquanto CEPR, mesmo baseando-se em dados da Ecorys, assume que apenas $25 \%$ das medidas não tarifárias serão eliminadas.

Três estudos (Bertelsmann; CEPR; CEPII) mostram que as exportações bilaterais americanas sofreriam maiores aumentos que as europeias. A Tabela 2 sintetiza esses números: 
Tabela 2 - Aumento das exportações bilaterais líquidas previstas por estudos selecionados em decorrência da implantação do TTIP até 2027

\begin{tabular}{ccccccc}
\hline & \multicolumn{2}{c}{ CEPR } & \multicolumn{2}{c}{ CEPII } & \multicolumn{2}{c}{ Ecorys } \\
\hline & Exportações & Aumento & Exportações & Aumento & Exportaçóes & Aumento \\
& Bilaterais & Líquido & Bilaterais & Líquido & Bilaterais & Líquido \\
UE & $28,0 \%$ & $5,9 \%$ & $48,0 \%$ & $7,6 \%$ & $2,1 \%$ & $0,9 \%$ \\
EUA & $36,6 \%$ & $8,0 \%$ & $52,0 \%$ & $10,1 \%$ & $6,1 \%$ & $2,7 \%$ \\
\hline
\end{tabular}

Fonte: Capaldo (2014).

Dois estudos (Ecorys, CEPR) preveem a mesma evolução para o PIB. A margem de crescimento, considerando-se os quatro trabalhos, fica entre 0,32 e 1,31\% para a UE e 0,13 e 4,82 \% para os EUA. As estimativas são calculadas para determinado momento, por exemplo, no CEPR, o período é 2017-2027, logo, o aumento de $0,48 \%$ do PIB da UE seria o valor adicionado pelo acordo até 2027. A Tabela 3 sintetiza tais resultados:

Tabela 3 - Aumentos do PIB dos EUA e da UE em 2027 previsto por estudos selecionados em decorrência da implantação do TTIP

\begin{tabular}{cccc}
\hline & Ecorys & CEPR & Cepii \\
\hline UE & $0,34 \%$ & $0,49 \%$ & $0,30 \%$ \\
EUA & $0,13 \%$ & $0,40 \%$ & $0,30 \%$ \\
\hline
\end{tabular}

Fonte: Capaldo (2014).

Microeconomicamente, os setores mais competitivos são os que mais se beneficiariam da liberalização do comércio, elevando sua produção e exportação. Enquanto o mesmo setor em outra economia não conseguiria competir com preços mais baixos, substituindo sua produção interna pelas importações.

Os efeitos do acordo de livre comércio sobre os salários reais seguem a mesma lógica dos efeitos sobre o PIB. Setores mais produtivos permitiriam uma melhor remuneração do trabalho. Trabalhadores não qualificados teriam seus salários reais aumentados entre 0,36 e $0,51 \%$, enquanto que trabalhadores qualificados teriam entre 0,34 e $0,50 \%$ de elevação. 


\section{Visões contrárias ao acordo}

O item a seguir trata das principais contribuições acadêmicas que suportam posições contrárias à implantação do TTIP sem sua forma atual, decorrente da percepção de que, ao invés de um acordo "ganha-ganha", ele poderia desencadear resultados negativos para a UE. O subitem 3.1 apresenta a visão de Capaldo (2014). A seguir, no subitem 3.2, os questionamentos e qualificações do relatório do OFSE (2014) são visitados.

\subsection{Capaldo (2014)}

De acordo com esse autor, a literatura resenhada no item anterior vem apresentando vários problemas na avaliação dos efeitos do TTIP, e não oferece base sólida para a tomada de decisões sobre o acordo. Aponta-se que o modelo de equilíbrio geral computável, empregado por todos os trabalhos acadêmicos favoráveis ao acordo, pode ser considerado inadequado para analisar seus resultados.

Partindo de projeções de um cenário base para as variáveis macroeconômicas chave no período 2015-2025 por país ou bloco de países, o trabalho emprega as mesmas estimativas microeconômicas de crescimento das exportações geradas pelos trabalhos do item anterior para estimar os efeitos do acordo em relação ao cenário base. Porém, para analisar as consequências macroeconômicas do acordo, usa o Modelo de Política Global (GPM) das Nações Unidas, que engloba premissas diferentes sobre os mecanismos de ajuste da economia, a dinâmica de emprego e o comércio global das usadas pelos modelos de equilíbrio geral ${ }^{12}$.

Com base neste cenário modificado pelo acordo, Capaldo calcula as exportações líquidas considerando as retroalimentações sobre PIB e emprego em todos os países, inclusive os que não participam do acordo. Obtém a estimativa (Tabela 2) de que o TTIP levará a uma contração do PIB, da renda pessoal e do emprego na Europa, em oposição aos efeitos "ganha-ganha" dos trabalhos do item anterior. Também foi projetado um aumento da instabilidade financeira e uma tendência de queda da parcela de salários no PIB europeu. Conclui que o acordo beneficiaria os EUA em detrimento da integração europeia, conforme Tabela 4 a seguir:

12 Para uma crítica (quiçá exagerada) de Capaldo (2014), vide Bauer e Erixson (2015). 
Tabela 4 - Efeitos estimados de longo prazo (2025) do acordo TTIP em países e variáveis selecionadas

\begin{tabular}{cccc}
\hline & $\begin{array}{c}\text { Exportações } \\
\text { Líquidas } \\
\text { (\%PIB) }\end{array}$ & $\begin{array}{c}\text { Variação } \\
\text { adicional do } \\
\text { PIB (p.p.) }\end{array}$ & $\begin{array}{c}\text { Emprego } \\
\text { (mil unidades) }\end{array}$ \\
\hline EUA & $+1,02$ & $+0,36$ & +784 \\
Reino Unido & $-0,95$ & $-0,07$ & -3 \\
Alemanha & $-1,14$ & $-0,29$ & -134 \\
França & $-1,90$ & $-0,48$ & -130 \\
Itália & $-0,36$ & $-0,03$ & -3 \\
Outros do Norte da Europa & $-2,07$ & $-0,50$ & -223 \\
Outros do Sul da Europa & $-0,70$ & $-0,21$ & -90 \\
UE & & & -583 \\
\hline
\end{tabular}

Fonte: Capaldo (2014).

O TTIP levaria a redução de exportações líquidas europeias, a despeito da depreciação real do euro prevista frente ao dólar estadunidense. As economias do norte europeu sofreriam a maior perda (2,07 \% do PIB), seguidas pela França $(1,9 \%$ do PIB), Alemanha (1,14 \% do PIB) e Reino Unido (0,95\% do PIB).

No campo do emprego, calcula-se que cerca de 600 mil postos de trabalho sejam perdidos na UE, e que os países do norte europeu seriam os mais afetados (223.000 empregos), seguidos pela Alemanha (-134.000 empregos), França (-130.000 empregos) e países do sul europeu (-90.000 empregos). Curioso observar a ausência do cálculo do efeito na taxa de desemprego, mas como em 2016 a força de trabalho europeia correspondia a aproximadamente 214 milhões de pessoas (Eurostat, 2017), podemos estimar que esses números absolutos corresponderiam a um aumento de 0,28 p.p. na taxa de desemprego.

O possível acordo também provocaria desequilíbrios nas contas do governo, com os orçamentos públicos sofrendo deteriorações em todos os países da UE exceto Itália, entre os quais a França sofreria a maior perda (0,64 \% do PIB).

Se essas projeções se mostrarem verdadeiras, a interdependência transatlântica aumentaria a exposição da União Europeia às flutuações de demanda de importação dos Estados Unidos.

Enquanto as exportações bilaterais estão previstas para aumentar em mais de 60 \% para a União Europeia e mais de 80 \% para os Estados Unidos, espera-se que as exportações entre os países europeus diminuam entre 25 e $41 \%$.

Com relação ao resto do mundo, é citado o relatório OFSE (2014) como se referindo ao impacto global negativo do TTIP em termos de exportações globais, quando incluídos no cálculo os países que não fazem parte do acordo.

A maioria dos estudos prevê pequenos aumentos do PIB dos países, implicando então, em efeitos insignificantes sobre as taxas de crescimento do PIB anual. O 
estudo em questão, porém, prevê que, com exceção dos EUA (crescimento de 1,02 $\%$ ), haveria um impacto negativo no longo prazo sobre toda a UE, em especial sobre a Europa Setentrional $(-0,50 \%)$ e França $(-0,48 \%)$.

\subsection{OFSE (2014)}

A Fundação Austríaca para o Desenvolvimento da Pesquisa (OFSE) também financiou uma pesquisa para avaliar os benefícios do TTIP enfatizados na bibliografia favorável ao acordo. Após sintetizar os resultados por ela obtidos, o relatório final de Raza et al. (2014) - aqui denominado OFSE (2014) - chama atenção para uma série de custos de ajustamento que ocorrem em qualquer acordo comercial. Tais custos, porém, não foram incluídos na bibliografia pró-TTIP, o que pode complicar substancialmente a avaliação do seu impacto. Três principais tipos de custos de ajustamento econômicos são citados:

1) A liberalização comercial pode gerar ou aumentar déficits comerciais, induzindo depreciação substancial da moeda das regiões deficitárias em relação às superavitárias; tal movimento pode, por sua vez, elevar o endividamento de empresas que tomaram empréstimos em moeda estrangeira, com possíveis efeitos colaterais negativos sobre produção e emprego.

2) A redução ou eliminação das tarifas de importação (12\% das receitas tarifárias da UE antes do acordo) podem reduzir a receita pública, prejudicando o financiamento das contas públicas. Essa perda poderia ser em parte compensada se, e na medida em que, o acordo de fato propiciasse aumento do PIB e, portanto, das receitas tributárias associadas.

3) Setores expostos a forte concorrência logo após a liberalização reduziriam sua produção e consequentemente seu nível de emprego. Ainda que desconsiderando possíveis efeitos macroeconômicos mais severos, como os previstos em Capaldo (2014), ainda assim haveria redução de produção e emprego em alguns setores até a reorientação da força de trabalho para os setores nos quais a produção e o emprego se ampliassem, contraindo-os por certo período, bem como as receitas tributárias associadas.

A exclusão desses custos de ajustamento da análise, em especial o último, são atribuídos pelo relatório ao fato dos estudos de avaliação do impacto do TTIP terem empregado modelos de equilíbrio geral. Esses são considerados irrealistas, na medida em que supõem racionalidade individual ilimitada, e se baseiam na teoria do equilíbrio geral, que leva a microeconomia pura para uma análise na qual a macroeconomia é extremamente importante. 
Afora os custos estritamente econômicos citados, o relatório em questão chama a atenção para o fato de que há ainda custos sociais significativos associados à implantação do TTIP.

Como visto anteriormente, é unânime a ideia de que os benefícios do TTIP só se tornam significativos se o acordo conseguir incluir significativa redução das $\mathrm{MNTs}^{13}$. Curiosamente, tal visão frequentemente considerou as NMTs como fontes de perdas econômicas puras. Contudo, pelo menos em setores como produtos químicos, cosméticos ou fármacos e alimentos e bebidas, a eliminação das MNTs se torna complicada, uma vez que envolve a saúde da população e funciona como modo de prevenção para evitar gastos públicos com saúde. Isso significa que provavelmente os estudos pró-TTIP subestimaram a dificuldade de reduzir as MNTs e/ou desconsideraram o trade off entre ganhos econômicos e custos sociais de sua redução. Diante disso, um acordo mais amplo poderia gerar não só ganhos econômicos mais significativos, mas custos sociais também mais elevados, ou vice-versa. E mesmo os ganhos econômicos podem ser significativamente restringidos por possível elevação dos custos com a saúde pública.

No limite, não é claro se um acordo mais abrangente não implicaria até uma possível perda de bem-estar social (na medida em que os custos sociais mais do que compensassem os ganhos econômicos, deduzidos os custos de saúde). Também não é claro se em um acordo menos abrangente, menos ambicioso na redução das NMTs e portanto mais cuidadoso com os custos sociais, os reduzidos benefícios econômicos ainda justificariam os custos do próprio processo de negociação ${ }^{14}$.

O relatório recomenda ainda que se busque observar a experiência prática dos acordos de livre comércio existentes para aprender como melhor avaliar os projetos existentes. O Acordo de Livre Comércio Norte-Americano (Nafta) mostraria que todos os estudos realizados antes do acordo ignoraram que a maior parte dos custos de ajustamento recairia sobre o trabalhador. Os impactos positivos sobre o PIB real e o bem-estar foram inferiores aos esperados a partir dos modelos, e os salários nos países membros ficaram estagnados ou mesmo foram reduzidos, conforme a maioria das avaliações feitas após a aplicação do acordo. Segundo o Trade Adjustment Assistance (TAA), 845.000 trabalhadores perderam seus empregos nos EUA em razão do aumento das importações provenientes do Canadá e do México. Os empregos criados na indústria manufatureira apenas compensaram os empregos perdidos na agricultura.

13 OFSE (2014) observa ainda que as elasticidades-preço que geram tais resultados foram provavelmente superestimadas. Elasticidades-preço mais realistas (menores) gerariam ganhos substancialmente menores.

$14 \mathrm{O}$ relatório aponta ainda a enorme dificuldade em mensurar adequadamente as NMTs, bem como a precariedade das estimativas obtidas na literatura pró-TTIP. 
Mesmo sem apresentar estimativas novas, OFSE (2014) oferece uma importante crítica de aspectos vitais dos diversos trabalhos favoráveis ao TTIP, como a referente à omissão dos custos econômicos e sociais de ajustamento. Mas não trata das visões críticas ao acordo, nem compara os dois conjuntos de contribuições, tema que desenvolveremos no item seguinte.

\section{A macroeconomia e o comércio internacional}

Desde a crítica de Adam Smith aos mercantilistas, o debate em torno dos custos e benefícios da liberalização internacional do comércio sempre esteve presente na academia. Em momentos de crises mundiais severas, propostas protecionistas extravasaram o ambiente acadêmico, venceram o debate público e foram implantadas. Foi assim na grande crise do final do século XIX, na Grande Depressão do século XX, e assim tem sido desde a Grande Recessão iniciada em 2007-2008. Ao renegar os acordos de livre comércio, portanto, o Presidente Trump ecoa uma longa tradição, mas em contradição às teses liberais do seu próprio partido.

No campo estritamente acadêmico, o debate envolve ponderar os ganhos e perdas gerados pelos acordos internacionais de liberalização do comércio. Por um lado, o aprofundamento da especialização e da arbitragem internacional concernente aos preços dos fatores de produção, ao reduzirem os custos de produção e portanto os preços relativos dos bens e serviços, beneficiariam todos os países participantes dos acordos na posição de demandantes desses produtos $^{15}$, ainda que em diferentes graus.

Por outro, os custos associados à redistribuição geográfica da produção e, em particular, do emprego, concentrariam-se nos países que sofressem perda de exportações líquidas (e portanto da demanda agregada), em benefício dos países que as ampliassem, sejam eles participantes ou não dos acordos ${ }^{16}$.

Embora toda teoria que pretenda uma interpretação adequada dos efeitos dos acordos comerciais precise dispensar um tratamento acurado a ambos os pratos da balança - benefícios e custos -, a forma específica pela qual se dá essa ponderação depende intrinsecamente da teoria macroeconômica adotada.

$\mathrm{Na}$ teoria macroeconômica convencional, os fenômenos são separados em curto e longo prazo, definidos em função da existência ou não de equilíbrio no mercado de

15 Os países que não participam do acordo podem ser tanto beneficiados quanto prejudicados por ele. Beneficiados, pelo acesso a produtos mais baratos no exterior. Prejudicados, por potenciais desvios de comércio.

16 Tais custos incluem não apenas os aspectos relacionados diretamente à perda de produção e emprego, como também os fenômenos indiretamente a eles relacionados, como mudanças em taxas de câmbio, de juros e de inflação; na situação do balanço de pagamentos e níveis de endividamento em moeda estrangeira; bem como nas receitas e finanças públicas. Todos esses, por sua vez, poderiam gerar desdobramentos secundários em ainda outros fatores. 
trabalho. No curto prazo, o comportamento dos salários enfrenta diversos tipos de obstáculos - contratos nominais e/ou reais rígidos, custo na difusão de informações, etc., - que os impede de manter um equilíbrio permanente no mercado de trabalho. No longo prazo, contudo, tais obstáculos são superados, e o mercado de trabalho tenderia para seu equilíbrio, enquanto o produto convergiria concomitantemente para seu nível potencial.

Sob o prisma dessa teoria, os custos de ajustamento às mudanças decorrentes dos acordos comerciais seriam essencialmente de curto prazo. Países cujos níveis de produção e emprego caíssem em decorrência da queda das exportações líquidas sentiriam esses custos de ajustamento no curto prazo. No longo prazo, uma queda dos salários reais reequilibraria oferta e demanda por trabalho, de forma que o desemprego involuntário seria absorvido, enquanto a produção perdida nos setores menos competitivos seria mais do que compensada pelos setores beneficiados pela maior abertura comercial. Assim, os benefícios de longo prazo superariam os custos de curto prazo, com a teoria se mostrando favorável aos acordos comerciais ${ }^{17}$.

Por outra via, a teoria heterodoxa não imputa às mudanças nos salários a capacidade de operar como mecanismos equilibradores do mercado de trabalho. Quedas dos salários desencadeariam fenômenos macroeconômicos complexos, podendo, no limite, amplificar o desequilíbrio inicial do mercado de trabalho ao invés de saná-lo (Keynes, 1936, cap. 19; De Long e Summers, 1986; Seccareccia e Lavoie, 2016) ${ }^{18}$.

Se assim for, diferentemente da teoria convencional, na teoria heterodoxa não seria possível estabelecer uma hierarquia temporal entre ganhos e perdas gerados pelos acordos de liberalização comercial. Custos e benefícios precisariam ser pesados em pé de igualdade. Então, para que o país que perdesse exportações líquidas em decorrência do acordo pudesse beneficiar-se deste, precisaria dispor de mecanismos ou impor políticas governamentais compensatórias, capazes de gerar a absorção do desemprego e compensar eventuais déficits comerciais gerados pelo acordo.

Curiosamente, observando os diversos trabalhos que tentam avaliar os efeitos do TTIP, notamos que os dois conjuntos de contribuições aqui resenhados ostentam, em alguma medida, distorções importantes em relação às teorias macroeconômicas acima citadas, das quais supostamente haurem suas inspirações.

Observando o conjunto de contribuições de orientação mais liberal que baliza o suporte acadêmico ao TTIP, resenhado no item 2 deste trabalho, notamos uma curiosa assimetria nos pratos da balança: o uso de modelos de equilíbrio geral acarreta

17 Paralelamente, eventuais déficits ou superávits comerciais resultantes dos acordos teriam também caráter temporário, na medida em que o movimento da taxa de câmbio real tenderia a eliminar esses efeitos no longo prazo.

18 Também é possível que movimentos de longo prazo da taxa real de câmbio sejam incapazes de compensar déficits ou superávits comerciais e/ou de balanço de pagamentos decorrentes do acordo comercial. 
a suposição de que o mercado de trabalho permanece em equilíbrio durante todo o tempo. Isso implica, mesmo sob a ótica da mais rigorosa teoria convencional, eliminar de saída a existência mesma de custos (ainda que temporários) de ajustamento da economia ao choque representado pela introdução do plano. Eliminado o "prato dos custos”, o problema de avaliação dos efeitos do acordo fica limitado ao de estimar a distribuição dos benefícios entre as partes envolvidas na solução "ganha-ganha".

No que concerne à contribuição crítica de Capaldo (2014), algo similar ocorre, agora, sob o prisma da macroeconomia heterodoxa: a escolha do modelo macroeconômico agregado das Nações Unidas, um modelo puro de demanda agregada, também elimina de saída a possibilidade de acesso dos países participantes do TTIP aos seus benefícios de redução de preços relativos. Fez-se a crítica das contribuições convencionais incidindo no mesmo problema, porém na direção oposta: a escolha desse modelo excluiu de saída o "prato" dos benefícios. Por consequência, restringiu-se o problema da avaliação dos efeitos do TTIP ao de, essencialmente, estimar o tamanho do custo incidente sobre a região que sofreria queda das exportações líquidas - a UE. Desconsiderou-se ainda a possibilidade de acionar políticas econômicas capazes de compensar tais efeitos deletérios do acordo, de molde que ainda fosse a ela possível gozar de seus benefícios, evitando, ao menos parcialmente, tais custos.

Tanto no caso das contribuições ortodoxas quanto das heterodoxas havia equipamento teórico mais sofisticado, que poderia ter sido utilizado para estimar melhor os efeitos do acordo. Na ortodoxia, teria sido melhor empregar alguma versão do DSGE (Dynamic Stochastic General Equilibrium), dotado de reações diferenciadas de curto e de longo prazo. Na heterodoxia, era possível acoplar uma função de oferta agregada não vertical, bem como observar alternativas de política econômica capazes de compensar os efeitos deletérios.

Finalmente, cabe observar que os sistemas contemporâneos de metas de inflação, em operação tanto nos EUA quanto na Europa, aproximam os sistemas teóricos ortodoxo e heterodoxo, na medida em que a política monetária - e não apenas os ajustes salariais automáticos ${ }^{19}$ - passam a estabelecer caminhos alternativos para a promoção de ajustes entre oferta e demanda agregadas. A condução da política monetária pelo Banco Central passa a ser um fator importante a afetar a temporalidade dos desequilíbrios no mercado de trabalho e, portanto, os custos do ajuste ao acordo. Mas esse tema sequer foi mencionado pelos grupos de contribuições resenhadas.

Em tese, o acordo representaria choque de oferta positivo para todos os parceiros, e simultaneamente um choque de demanda, favorável para os parceiros com

19 Transferem o foco do debate para o comportamento da curva de Phillips e seus coeficientes de retroalimentação mais expectativas inflacionárias, e para a intensidade dos efeitos de histerese. 
acréscimo de exportações líquidas, ou desfavorável para os parceiros na situação oposta. Se a regra de política monetária implícita no sistema de metas de inflação (regra de Taylor) conseguir de fato aproximar o sistema econômico do seu nível de produção potencial, seria possível absorver ao menos parte do desemprego involuntário criado pelo acordo, reduzindo seu custo.

Nesse cenário, os ganhos de produtividade decorrentes do acordo desencadeariam redução da inflação em ambos os lados do Atlântico, o que ocasionaria tendência de redução dos juros reais pelos Bancos Centrais dos países envolvidos, em linha com o princípio de Taylor. Essa tendência seria mais forte no lado em que as exportações líquidas declinassem (provavelmente a UE). Esse declínio mais forte, por sua vez, tenderia a provocar depreciação real do euro em relação ao dólar, o que, por sua vez, tenderia a aumentar a competitividade em preço dos produtos europeus em relação aos estadunidenses, compensando, ao menos parcialmente, o previsto ganho inicial de exportações líquidas dos EUA.

É claro que o mecanismo em questão não deveria ser tratado como panaceia, como mostram os debates teóricos acerca da real capacidade do sistema em cumprir adequadamente sua função. ${ }^{20}$ Afora isso, porém, há que se levar ainda em conta que, em decorrência da recém encerrada crise mundial, as taxas de juros nominais se encontram, em ambos os lados do Atlântico, em níveis muito abaixo da média histórica. Isto poderia reduzir a capacidade de a política monetária absorver os choques decorrentes do acordo. Talvez por isso fosse recomendável inclusive postergar sua vigência para um futuro no qual as taxas de juros tivessem se normalizado. O que, aliás, abriria interessante discussão acerca do momento adequado para a sua implantação.

Mesmo que os sistemas de metas de inflação sejam incapazes de absorverem, por si só, o múltiplo choque representado pelo acordo, ainda seria possível operacionalizar políticas econômicas e sociais capazes de salvaguardar os países participantes contra os efeitos negativos remanescentes do acordo. Não apenas sobre a UE como um todo, mas também sobre aqueles setores específicos que, nos dois lados, fossem mais sensíveis aos seus efeitos.

\section{Considerações finais}

Procurou-se ao longo deste trabalho demonstrar que tanto o bloco de contribuições ortodoxas pró-TTIP quanto sua contraparte heterodoxa fizeram

20 A suposta tendência do sistema de metas de fazer a inflação convergir para a meta e, concomitantemente, o produto para o potencial, foi criticada por Blanchard et al (2010), que ironicamente apelidou-a de "coincidência divina". 
escolhas teóricas extremas, que acabaram por polarizar demasiada e desnecessariamente a discussão sobre o tema, empobrecendo-a.

Contribuições ortodoxas, baseadas em modelos de equilíbrio geral computável, trataram de enfatizar os ganhos potenciais do acordo, esquecendo-se dos significativos custos que poderiam atingir os parceiros comerciais, em particular os que sofressem reduções de exportações líquidas, como resultado da redução das NMTs.

A contraparte heterodoxa - especialmente o trabalho de Capaldo resenhado no item 3 - cometeu o equívoco similar e oposto de, lastreado em modelos macroeconômicos que omitiam potenciais efeitos benéficos do acordo pelo lado da oferta, enfocar apenas os possíveis custos oriundos da redução das exportações líquidas (e, portanto, da demanda agregada) na UE. Desconsiderou ainda a possibilidade de que políticas econômicas e sociais de salvaguarda pudessem ser acionadas para minimizar os efeitos colaterais negativos do acordo, em prol da prevalência dos aspectos positivos.

O presente artigo procurou mostrar ainda que a consideração do possível efeito estabilizador do sistema de metas de inflação, no sentido de reduzir os potenciais impactos negativos de acordo, em paralelo a outras políticas e mecanismos macro e microeconômicos de salvaguardas, poderiam ter enriquecido sobremaneira a discussão. Poderia inclusive ter gerado algum terreno comum que servisse de palco mais adequado ao debate, na medida em que permitisse contemplar tanto seus potenciais ganhos quanto seus custos, e o momento apropriado de sua implantação.

Considerando que ambos os lados do debate dispunham de instrumental teórico e aplicado mais sofisticado do que o utilizado, que permitissem sopesar mais cautelosamente os dois "pratos da balança" do acordo - ganhos e custos potenciais -, não deixa de ser curioso cogitar acerca das razões para a adoção de posturas tão marcadamente polares. Uma consideração mais detalhada desses aspectos, porém fugiria ao escopo do presente artigo.

Quaisquer que tenham sido os interesses que guiaram o debate acadêmico para esse rumo, o fato é que sua polarização acabou por gerar seus próprios custos. Em primeiro lugar, deixou-se de enfatizar que os resultados esperados do TTIP eram de segunda ordem, tanto em termos do possível impacto positivo no longo prazo, quanto do seu potencial efeito negativo no curto prazo (especialmente na UE). Esse aspecto é visível nos dois grupos de contribuições, que buscaram por vezes escondêlo, recorrendo ao artifício de tratar dos impactos do acordo em termos de números absolutos, ao invés de relativos.

Ademais, essa polarização transmitiu ao debate público a clara sensação de que os trabalhos acadêmicos partiam de posições pré-estabelecidas em prol ou contra o TTIP; que não tinham qualquer caráter científico que pudesse informar 
adequadamente a tomada de posições acerca do acordo, servindo apenas como instrumento de retórica na defesa dessas posições.

Que os acontecimentos acerca dos acordos comerciais nos sirvam de lição sobre a importância de a ciência fazer seu trabalho de forma mais cautelosa e ponderada, se quisermos preservar nosso espaço no debate público.

\section{Referências}

BAUER, Matthias, e ERIXON, Friedrich. "Splendid Isolation" as Trade Policy: Mercantilism and Crude Keynesianism in the "Capaldo Study" of TTIP. ECIPE (European Center for International Political Economy) Occasional Paper 03/2015.

BIZARRI, Kim. A Brave New Transatlantic Partnership. The proposed EU-US Transatlantic Trade and Investment Partnership (TTIP/TAFTA), and its socioeconomic E environmental consequences. Bruxelas: Seattle to Brussels Network, 2013.

BLANCHARD, Olivier, DELL'ARICCIA, Giovanni, e MAURO, Paolo. Rethinking macroeconomic policy. IMF Staff Position Note, SPN/10/03, 2010. DOI: https://doi.org/10.5089/9781455224982.004.A001

CAPALDO, Jeronim. The Trans-Atlantic Trade and Investment Partnership: European Disintegration, Unemployment and Instability. Medford: GDAE Working Paper, 2014.

DE LONG, J. Bradford e SUMMERS, Lawrence H. Is increased price flexibility stabilizing? The American Economic Review, p. 1031-1044, 1986. DOI: https://doi.org/10.3386/w1686

ECORYS Nederland BV Non-Tariff Measures in EU-US Trade and Investment: an economic analysis. Roterdã: Ecorys Final Report, 2009.

EUROSTAT. Workforce for 28 countries of European Union in 2016. Disponível em http://appsso.eurostat.ec.europa.eu/nui/show.do?dataset=lfsi_emp_a\&lang=en Visitada em 10.08.2017.

FELBERMAYR, Gabriel, HEID, Benedikt, e LEHWALD, Sybille TransAtlantic Trade and Investment Partnership (TTIP): Who benefits from a free trade deal? Gütersloh: Bertelsmann Stiftung, 2013. 
FELBERMAYR, Gabriel, JUNG, Benjamin e LARSCH, Mario. "Icebergs versus Tariffs: A Quantitative Perspective on the Gains from Trade", CESifo Working Paper No. 4175, 2013a.

FONTAGNÉ, Lionel, GOURDON, Julien e JEAN, Sébastian. Transatlantic trade: Whither partnership, which economic consequences? Paris: Centre d'Etudes Prospectives et d'Informations Internationales (CEPII), 2013.

FRANÇOIS, Joseph et al. Reducing Transatlantic Barriers to Trade and Investment. Londres: CEPR (Centre for Economic Policy Research), 2013.

FUNDO MONETÁRIO INTERNACIONAL Report for Selected Countries and Subjects. In: http://www.imf.org/external/pubs/ft/weo/2016/01/weodata/ Site visitado em 26.04.2016.

KEYNES, John Maynard. The General Theory of Employment, Interest and Money. Londres: Macmillan, 1936.

LOPES DA SILVA, Mygre, CORONEL, Daniel A. e ABBADE DA SILVA, Rodrigo. O Impacto da Parceria Transatlantica de Comércio e Investimento (TTIP) para a Economia Brasileira. Pesquisa e Planejamento Econômico, v. 47, no. 1, abril de 2017. DOI: https://doi.org/10.4013/pe.2015.112.05

RAZA, W., J. GRUMILLER, TAYLOR, L., TRÖSTER, B. e von ARNIM, R. Assess_TTIP: Assessing the Claimed Benefits of the Transatlantic Trade and Investment Partnership (TTIP). Viena: OFSE, 2014.

SECCARECCIA, Mario; LAVOIE, Marc. Understanding the Great Recession: Some Fundamental Keynesian and Post-Keynesian Insights, with an Analysis of Possible Mechanisms to Achieve a Sustained Recovery. Working Paper n. 37, Institute for New Economic Thinking, 2016. DOI: https://doi.org/10.2139/ssrn.2735581

UNIÃO EUROPEIA European Union, Trade in Goods with USA. Bruxelas: Directorade-General for Trade, 2015.

Recebido em 24.08.17

Aprovado em 14.01.19 